\title{
O DUPLO PAPEL DA JUDICIALIZAÇÃO DA SAÚDE: LIMITES E DESAFIOS
} THE DUAL ROLE OF HEALTH JUDICIALIZATION: LIMITS AND CHALLENGES

\author{
Ana Paula de Jesus Souza*
}

A judicialização das demandas de saúde envolve um debate paradoxal que precisa ser discutido. O estado caótico na seara da saúde e a latente omissão estatal têm contribuído para crescente procura do judiciário na promoção de políticas públicas de competência típica do poder executivo e legislativo. A linha é tênue entre a necessidade de poder judiciário para efetivar o acesso direito á saúde e o excesso de justiça na promoção dessas políticas públicas. Nesse aspecto, objetiva-se ponderar os limites para o julgamento de ações no âmbito da saúde e os desafios do excesso de justiça em tempos de crises.

Palavras-chaves: direito à saúde; paradoxo; judicialização; excesso; efetividade.

The judicialisation of health demands involves a paradoxical debate that needs to be discussed. The chaotic state in the health sector and the latent state omission have contributed to the growing demand of the judiciary in the promotion of public policies of competence typical of the executive and legislative power. The line is tenuous between the need for the judiciary to enforce access to health and excess justice in the promotion of these public policies. In this aspect, the objective of the present study is to consider the limits to the judgment of health actions and the challenges of excess justice in times of crisis.

Key words: right to health; paradox; judicialisation; excessive; effectiveness

\footnotetext{
*Advogada. Mestranda em Direito pela Universidade Federal de Sergipe (UFS). Especialista em Direito do Estado pelo Centro Universitário Guanambi (UniFG). Pesquisadora e bolsista vinculada à Fundação de Apoio à Pesquisa e à Inovação Tecnológica do Estado de Sergipe- FAPITEC. E-mail: paulasouzaap@ hotmail.com. 


\section{INTRODUÇÃO}

A Constituição Federal de 1988 inovou no ordenamento jurídico brasileiro promovendo o direito à saúde a uma norma de cunho social/fundamental. As normas dispostas nos artigos $6^{\circ}$ e $196^{\circ}$ a $200^{\circ}$ da constituição traduzem o acesso direito e universal da saúde e a necessidade de implementação de políticas públicas neste âmbito. Sem embargo, o direito à saúde no Brasil passa por um momento sombrio, a ausência de políticas públicas tem trazido impactos negativos para sociedade brasileira, que padece com a falta de tratamentos básicos de saúde.

Diante das omissões, o poder judiciário tem se tornado um protagonista na efetivação de políticas públicas, e, com isso, surge um debate paradoxal, o poder judiciário tem um papel essencial na concretização deste direito social? Ou estamos vivendo a era do excesso de justiça e afronta direta do princípio da separação dos poderes?

À vista de tantas indagações elementares, o presente artigo disporá de três seções e a conclusão. A primeira parte analisará a construção ideológica do direito à saúde em documentos internacionais e, bem como, na inovadora constituição de 1988 que voltou os olhares para a necessidade da ascensão do direito à saúde como norma social/fundamental e promoção de políticas públicas pelo e Estado e todos os cidadãos. A segunda seção examinará a nova onda de protagonismo do poder judiciário na execução de políticas pública e o quanto esta centralidade pode ou não ultrajar o princípio da separação dos poderes. A última parte promoverá uma análise do paradoxo da judicialização da saúde, considerando os aspectos positivos e negativos que o movimento pode causar, buscando entender quais os motivos leva os cidadãos a buscarem e acreditarem no judiciário com órgão único na concretização de políticas públicas, apontando, ainda, os limites e desafios na promoção de políticas públicas na seara da saúde. O presente estudo será realizado por meio de levantamento bibliográfico em livros e artigos científicos. Ressalta-se ainda que o método de pesquisa utilizado será o dialético, objetivando uma análise das nuances da judicialização excessiva em tempos de crises.

\section{DO DIREITO À SAÚDE}


A Organização Mundial de Saúde (OMS) construiu o conceito de saúde como “o completo bem-estar físico, mental e social e não somente a ausência de doenças ou agravos", todavia, é salutar ressaltar que, não obstante a Organização Mundial de Saúde seja de um órgão destinado a debater questões na seara da saúde, o conceito foi construído em 1946, e encontra-se ultrapassado, considerando que a saúde não significa, tão somente, o pleno bem estar físico, mental ou social, mas envolve outros fatores. (SILVA, 2006, p. 767).

O conceito de saúde reveste-se de abstração e imaterialização, podendo envolver diversos elementos subjetivos e objetivos ao mesmo tempo, a definição avança e tem compreendido não só a ausência de doenças ou agravos, mas a necessidade de um meio ambiente ecologicamente equilibrado, saneamento básico, alimentação, lazer, bem estar físico, social e psicológico.

É inquestionável a necessidade de promoção do direito à saúde para o progresso da humanidade. Diante das atrocidades resultantes da segunda guerra mundial, os organismos internacionais passaram a refletir sobre a necessidade de se proteger os direitos, não só os civis e políticos, mas também os direitos econômicos, sociais e culturais. Em resposta, surgiu a Declaração Universal dos Direitos Humanos de 1948, que influenciou as nações democráticas a resguardar os direitos humanos. No âmbito da saúde, não foi diferente, o documento internacional ressaltou a urgência em assegurar a tutela desse direito de cunho singular.

Art. XXV - Todo homem tem direito a um padrão de vida capaz de assegurar a si e a sua família saúde e bem-estar, inclusive alimentação, 16 vestuário, habitação, cuidados médicos e os serviços sociais indispensáveis, e direito à segurança em caso de desemprego, doença, invalidez, viuvez, velhice ou outros casos de perda dos meios de subsistência em circunstâncias fora de seu controle.

O cerne da Declaração Universal dos Direitos Humanos foi pôr em destaque o princípio da universalidade dos direitos humanos, após a sua promulgação as nações passaram a voltar os olhares para a proteção e concretização dos direitos sociais/ humanos.

No Brasil, o movimento de Reforma Sanitária teve um papel singular para a efetivação do direito á saúde na constituição, com o objetivo em incentivar a criação Sistema único de Saúde, com fulcro em promover a universalização e a constitucionalização do direito à saúde.

De acordo com Flávia Bahia, (2008, p. 75): 
Com a efervescência da queda da ditadura militar, o processo de "redemocratização" reabriu as portas para o chamado de Movimento Sanitário e foi a conjuntura reservada para a instalação da $8^{\text {a }}$ Conferência Nacional de Saúde, marco pré-constituinte, que ocorreu entre 17 a 21 de março de 1986. Seu relatório final propôs a implantação do Sistema Único de Saúde (SUS), projeto antigo da população brasileira, que foi materializado pelo art. 198 do texto da Constituição de 1988.

A fase pré-constituinte trouxe a tona inúmeras questões relacionada á saúde, inclusive construindo uma definição conceitual de saúde na $8^{\mathrm{a}}$ Conferência Nacional de Saúde, em seu tema $1^{\circ}$, enfatizando a abstração conceitual.

Nesse sentido, assim dispõe o tem $1^{\circ}$ da Conferência Nacional de Saúde:

Em seu sentido mais abrangente, a saúde é a resultante das condições de alimentação, habitação, educação, renda, meio ambiente, trabalho, transporte, emprego, lazer, liberdade, acesso e posse da terra e acesso a serviços de saúde. É, assim, antes de tudo, o resultado das formas de organização social da produção, as quais podem gerar grandes desigualdades nos níveis de vida.

O direito à saúde possui importância singular por ser um direito intrinsecamente ligado ao direito á vida. Malgrado a sua relevância, o direito á saúde, no Brasil, ganhou o prestígio e ascensão com a promulgação da Constituição de 1988, que reservou espaço dotado de singularidade para o direito á saúde.

$\mathrm{Na}$ onda do constitucionalismo de cunho democrático/social, pós segunda guerra mundial, a Constituição Federal passou a prever em seus arts. $6^{\circ}, 196^{\circ}$ a $200^{\circ}$ o direito social á saúde, delineando mecanismos de proteção e aplicabilidade deste direito, considerando a necessidade de implementação por meio de políticas públicas para a integral efetividade da saúde. (SARLET, FIGUEIREDO, 2009, p. 3).

Constituição brasileira prevê em seu art. $6^{\circ} \mathrm{o}$ direito social à saúde, como norma de eficácia plena e aplicabilidade integral.

Art. $6^{\circ}$ São direitos sociais a educação, a saúde, a alimentação, o trabalho, a moradia, o transporte, o lazer, a segurança, a previdência social, a proteção à maternidade e à infância, a assistência aos desamparados, na forma desta Constituição. 
A construção evolutiva do direito à saúde como direito social denota a insurgência do Estado em expor de forma objetiva o direito saúde como normal basilar para vida e dignidade de qualquer ser humano, tendo como objetivo assegurar o dever do Estado em promover a prevenção e o reparo da saúde de qualquer cidadão, não obstante o patamar de direito social, o constituinte ainda expôs mecanismos claros e direitos de efetivação da saúde em seu art. 196, in literis:

Art. 196. A saúde é direito de todos e dever do Estado, garantido mediante políticas sociais e econômicas que visem à redução do risco de doença e de outros agravos e ao acesso universal e igualitário às ações e serviços para sua promoção, proteção e recuperação.

Hodiernamente, a saúde tem sido considerando não só um direito social, mas uma norma fundamental para construção de uma sociedade justa, igualitária e solidária. $\mathrm{Na}$ perspectiva de Ingo Wolfgang Sarlet, é um típico direito-dever do Estado e de todos.

Nesse contexto, pode-se observar que os deveres fundamentais relacionados ao direito à saúde, a depender do seu objeto, podem impor obrigações de caráter originário, como no caso das políticas de implementação do SUS, da aplicação mínima dos recursos em saúde e do dever geral de respeito à saúde, ou obrigações de tipo derivado, sempre que dependentes da superveniência de legislação infraconstitucional reguladora, cuja hipótese mais eloquente talvez se encontre na obediência às mais variadas normas em matéria sanitária (nos campos penal, administrativo, ambiental, urbanístico, etc.). Ademais, se os exemplos demonstram que o principal destinatário dos deveres fundamentais é certamente o Estado, fato reiterado pelas expressões usadas no texto constitucional, isso não afasta uma eficácia no âmbito privado, sobretudo em termos de obrigações derivadas. Neste sentido, aliás, cumpre destacar que a noção de deveres fundamentais conecta-se ao princípio da solidariedade, no sentido de que toda a sociedade é também responsável pela efetivação e proteção do direito à saúde de todos e de cada um, no âmbito daquilo que Canotilho denomina de uma responsabilidade compartilhada (shared responsability), cujos efeitos se projetam no presente e sobre as futuras gerações, como já reconhecido na seara do direito ambiental. (SARLET, FIGUEIREDO, 2008, p. 7).

O reconhecimento do direito á saúde como um direito fundamental/social não dispensa a necessidade de políticas públicas, a promoção do direito à saúde previsto no art. 196 da Constituição Federal presume ações concretas do poder público, havendo discricionariedade da administração pública para efetivá-las. Assim, não obstante a necessidade de implementação de políticas públicas, a referida norma é revestida de integralidade, sendo dotada de conteúdo programático e eficácia plena. 
Notadamente, a doutrina majoritária afirma que normas fundamentais, como a saúde tem força normativa própria, com total eficácia, devendo o poder público promover os meios e finalidades para a concretização dessas normas constitucionais de caráter fundamental.

Não obstante a imposição direta para a efetivação da saúde, a constituição não destrinchou quais os meios de efetivação das normas constitucionais referentes ao tema em questão, somente impõe ao Estado o dever de concretizar políticas públicas, de forma discricionária. As prestações positivas são de competência originária do poder público, todavia, tal fato não isenta a execução dessas condutas por pessoas jurídicas de direito privado e ou por pessoa física. A constituição permite a assistência à saúde por meio de iniciativa privada, mediante contratos públicos ou convênios, conforme se observa no seu art. 197, com intuito em promover a assistência a saúde e resguardar a dignidade humana. (SARLET, FIGUEIREDO, 2009, p. 12).

\section{A JUDICIALIZAÇÃO DA PÓLÍTICA E O PAPEL HERÓICO DO JUDICIÁRIO: AFRONTA A SEPARAÇÃO DOS PODERES?}

O neoconstitucionalismo trouxe importantes inovações no processo interpretativo do direito e tem sido basilar para a ascensão do poder judiciário no poder decisório de políticas públicas. O movimento, acunhado por Miguel Carbonell e difundido por Susanna Pozzolo surgiu como um modelo interpretativo transformador do ideário pós-positivista, projetando assegurar um processo ideológico de constitucionalização do direito que visa assegurar de modo veemente a proteção dos direitos fundamentais. (CARBONELL, 2003, p. 84).

O ideário desabrochou com o intento de unificar um sistema pós-positivista com algumas nuances jusnaturalista, com fulcro central em extrair os aspectos positivos de cada sistema, e conceber um sistema constitucional alicerçado sob o enfoque jusfilosófico. (POZZOLO, 2005, p. 232).

O modelo neoconstitucional, notoriamente, trouxe um novo olhar acerca da proteção dos direitos fundamentais, considerando que a lei maior passou a ser interpretada sob o prisma axiológico, reconhecendo a normatividade e elevando de modo mais plural os direitos e garantias fundamentais, tornando a constituição com elemento central do ordenamento jurídico. (NOVELINO, 2015, p.65).

Notadamente, o modelo interpretativo possibilitou que o judiciário fosse um sistema aberto a resolução de conflitos individuais e coletivos, com esse avanço, o processo de 
judicialização da política passou a ser uma realidade não Brasil e o judiciário tornou-se protagonista na promoção das políticas pública. De certo, o fenômeno da judicialização da política parece trazer um refrigério para os cidadãos que buscam o acesso a justiça e a resolução dos seus conflitos individuais e coletivos. No entanto, a judicialização da política também envolve questões profundas que põe a prova o princípio da separação do poderes.

Preliminarmente, é salutar entender que a judicialização da política não envolve questões construídas com uma base no sentido partidário, visto que a função política é exercida pelo precípuo órgão do legislativo, o termo envolve a possibilidade de que os direitos metaindividuais e coletivos sejam levados ao poder judiciário que resolverá a lide e promoverá uma política pública antes omitida pelo Estado. (MANCUSO, 2011, p.76)

De forma irreparável, Mancuso (2011, p.76) define o conceito de judicialização da política evitando contradições que o próprio nome possibilita:

\begin{abstract}
Para que a expressão judicialização da política preserve a devida clareza e densidade conceitual e não se disperse em indesejável vacuidade ou latitude excessiva, ela há de significar o acesso à justiça de controvérsias envolvendo as diversas políticas públicas programadas ou implantadas pelo Estado, assim, por exemplo, a de recursos hídricos e geração de energia (v.g., construção da hidrelétrica de Belo Monte, contestada em ações civis públicas propostas pelo Ministério Público Federal) ou aquela que objetiva a irrigação do semiárido mediante a captação das águas do Rio São Francisco (objeto de ações civis públicas movidas pelo Ministério Público Federal)_ Ainda, poderiam ser lembradas as ações populares que há tempos foram propostas objetivando impedir a iniciativa governamental de privatizar empresas estatais (política de gestão do chamado custo Brasil) e as ações civis públicas que buscavam impedir o plantio e comercialização de produtos transgênicos (política de saúde pública e regulação do agro negócio).
\end{abstract}

Hodiernamente, ante as omissões na seara das políticas públicas o poder judiciário passou a ser um balcão de reclamações, ganhando uma proporção preocupante na federação brasileira, considerando a latente necessidade de preservação da harmonia entre os poderes. A problemática gira em torno do convencimento generalizado da população em confiar veementemente nas decisões do poder judiciário com o único poder capaz de efetivar satisfatoriamente as omissões.

Por outro ângulo, a judicialização não pode ser considerada uma anomalia, haja vista que todas as decisões estão firmadas no centro da legalidade. A única constatação irretocável é que a judicialização das políticas públicas é uma realidade. 
A teoria da separação dos poderes, inicialmente construída por John Locke apregoava a separação mais rígida do poderes e um super poder legislativo.

Em todo caso, enquanto o governo subsistir, o legislativo é o poder supremo, pois aquele que pode legislar para um outro lhe é forçosamente superior; e como esta qualidade de legislatura da sociedade só existe em virtude de seu direito de impor a todas as partes da sociedade e a cada um de seus membros leis que lhes prescrevem regras de conduta e que autorizam sua execução em caso de transgressão, o legislativo é forçosamente supremo, e todos os outros poderes, pertençam eles a uma subdivisão da sociedade ou a qualquer um de seus membros, derivam dele e lhe são subordinados. (LOCKE, 1998, p.76).

A definição ideológica tratada no livro o Segundo Tratado Sobre o Governo Civil é pautada na importância do legislativo e a necessidade de separação mais rígida dos poderes inicialmente pensada como legislativo, federativo e executivo. Ao poder legislativo, incumbe a necessidade de usar a força da comunidade para sua autoproteção, o executivo, caberia a execução das leis e ao federativo, a resolução de conflitos.

O ideário Lockeano logo foi aperfeiçoado na obra do "Do espírito das Leis" pelo Barão de Montesquieu, o princípio da separação dos poderes foi contornado com bases mais sólidas, criando a necessidade de se pensar num atmosfera harmônica dos poderes. (FIGUEIREDO, GIBRAN, 2016, p. 108).

Quando, na mesma pessoa ou no mesmo corpo de magistratura, o poder legislativo está reunido ao poder executivo, não existe liberdade; porque se pode temer que o mesmo monarca ou o mesmo senado crie leis tirânicas para executá-las tiranicamente. Tampouco existe liberdade se o poder de julgar não for separado do poder legislativo e do executivo. Se estivesse unido ao poder legislativo, o poder sobre a vida e a liberdade dos cidadãos seria arbitrado, pois o juiz seria legislador. Se estivesse unido ao poder executivo, o juiz poderia ter a força de um opressor. Tudo estaria perdido se o mesmo homem, ou o mesmo corpo dos principais, ou dos nobres, ou do povo exercesse os três poderes: o de fazer as leis, o de executar as resoluções públicas e o de julgar os crimes ou as querelas entre os particulares. (MONTESQUIEU, 2000, p. 167).

Teoria tripartite pressupõe a harmonia e independência entre os poderes e não impõe um rompimento rígido entre os poderes. No Brasil, as definições de funções típicas e atípicas de governo demonstram uma interdependência e mutualidade entre os poderes. Destarte, o fenômeno da judicialização das políticas públicas não parece uma afronta direta ao princípio vetor da república federativa, considerando que não há violação a legalidade estrita a análise 
de políticas públicas por meio do judiciário. No entanto, isso não significa que o poder judiciário possa ser definido como um poder heróico, ilimitado e irrestrito.

\section{A JUDICIALIZAÇÃO DA SAÚDE: UM DEBATE PARADOXAL}

O fenômeno da judicialização das políticas públicas na será da saúde tem promovido um gigantesco debate acadêmico e jurídico, considerando que se trata de uma tentativa de efetivação desse direito tão singular, diante das omissões do Estado. O maior e mais profundo questionamento que assombra a maioria dos juristas concerne na seguinte questão: o que fazer como a crescente a judicialização do direito à saúde?

Preliminarmente, faz-se necessário compreender a dimensão que estamos tratando neste artigo, a judicialização da saúde envolve diversos tipos de situações, que segundo a doutrina majoritária merece um tratamento diferenciando. A judicialização da saúde pode ser compreendida desde um pleito de fornecimento de um tratamento simples e medicamentos que deveriam ser fornecidos pelo sistema único de saúde (SUS) ou até um pleito extraordinário de fornecimento de medicamento fora do rol autorizado pela agência de vigilância sanitária (ANVISA). Sob esse prisma, nota-se a necessidade de se observar cada caso concreto para se responder questões lacônicas como a posta no início desse capítulo, um resposta categórica mostra-se um tanto simplista diante do denso cenário. No entanto, é salutar ressaltar os limites e desafios da judicialização da saúde, considerando a sua latente complexidade.

A constituição federal traduz em seu bojo mecanismos para efetivação do direito à saúde, inclusive aduz a necessidade de implementação de políticas públicas, todavia, é notório que as normas que conteúdo programático depende de concretização por meio do Estado e de particulares. A ascensão do direito à saúde na constituição também influenciou na criação da Lei 8.080/99, a Lei Orgânica da Saúde, criada com fulcro em estruturar o Sistema Único de Saúde e promover a universalização deste direito singular.

Sem dúvidas, uma das maiores dificuldades encontradas no âmbito da saúde é a efetivação dos serviços básicos de saúde, a cruel realidade no estado brasileiro contribui para o crescimento desenfreado da judicialização e esse movimento precisa ser estudado com mais afinco. 
Os ensinamentos de Barroso (2010, p.437) corroboram o crescimento da judicialização das relações sociais.

Uma das instigantes novidades do Brasil dos últimos anos foi a virtuosa ascensão institucional do Poder Judiciário. Recuperadas as liberdades democráticas e as garantias da magistratura, juizes e tribunais deixaram de ser um departamento técnico especializado e passaram a desempenhar um papel político, dividindo espaço com o Legislativo e o Executivo. Tal circunstância acarretou uma modificação substantiva na relação da sociedade com as instituições judiciais, impondo reformas estruturais e suscitando questões complexas acerca da extensão de seus poderes.

O protagonismo exacerbado do judiciário e as decisões imbuídas de emoções proferidas pelos magistrados brasileiros têm sido estudados em países como Portugal, onde se busca compreender os reflexos da centralidade deste poder e as consequências do movimento pode acarretar, promovendo um grande debate acerca do neoconstitucionalismo.

É sabido que a saúde é um tema interdisciplinar que envolve outras áreas como medicina, política, economia, logo, não se faz necessário expor grandes argumentos para observar a necessidade de concretizar este direito social, que se encontra intrinsecamente ligado ao direito à vida e a dignidade da pessoa humana. No entanto, a crescente judicialização não tem contribuído para mudanças satisfatória nos serviços de saúde e tampouco nas políticas públicas que envolve a temática. (CARDOSO, 2017, p.47)

Devido a constante omissão estatal, o judiciário passou a ser analogicamente comparado a um balcão de reclamações, ganhando confiança da população e sendo tratado com único caminho para efetivação dos direitos sociais. Por um lado, a sensação da população brasileira não é incompreensível, haja vista que a ausência de serviços mínimos na seara da saúde só corrobora a falta de atuação estatal, que, atualmente, tem sido suprida pelas decisões de judiciais. Nesse norte, é fácil compreender que a omissão precede a judicialização e a culpa não pode ser jogada nas costas da população que busca a efetivação de um direito social por meio do judiciário.

Barroso (2012, p.9), sinaliza a necessidade de se observar o duplo papel da judicialização:

O fenômeno tem uma face positiva: o Judiciário está atendendo a demandas da sociedade que não puderam ser satisfeitas pelo parlamento, em temas como greve no serviço público, eliminação do nepotismo ou regras eleitorais. $\mathrm{O}$ aspecto negativo é que ele exibe as dificuldades enfrentadas pelo Poder Legislativo - e isso não se passa apenas no Brasil - na atual quadra histórica. A adiada reforma política é uma necessidade dramática do 
país, para fomentar autenticidade partidária, estimular vocações e reaproximar a classe política da sociedade civil.

O debate paradoxal da judicialização tem uma questão de ser, dado que envolve um protagonismo do judiciário de um lado e a ostentação orçamentária em casos de enfermidades peculiares e, por outro lado, compreende a efetivação do direito fundamental à saúde diante do denso cenário brasileiro.

É necessário salientar, mais uma vez, que a judicialização pode envolver caso singulares, como o pedido de fornecimento de medicamentos fora do rol da ANVISA e cirurgias complexas. Nesse caso, a atuação do judiciário precisa obedecer a limites para a proteção da máquina estatal, deve-se utilizar parâmetros legais e ponderar, com base nos princípios da proporcionalidade (necessidade, adequação e proporcionalidade em sentido estrito) e a razoabilidade.

Por esse ângulo, a ponderação principiológica e o auxílio interdisciplinar de Núcleos de Atendimento à Saúde podem contribuir na análise das demandas sociais. De certo que a centralidade do judiciário o tornou um poder prestacional, sendo instado a se manifestar sobre questões sociais. Entretanto, faz-se necessário analisar os pontos negativos dessa prática corriqueira, haja vista que a análise de questões que envolvem a prática são deferidas, muitas das vezes, pelo critério da emoção.

Nesse aspecto, o judiciário necessita de um apoio externo para apreciar a demandas da saúde, para evitar a má fé de alguns cidadãos que se utilizam da via judicial para "furar fila" ou buscam o deferimento de um tratamento de saúde mesmo com condições financeiras de custeá-lo. É notório que a população mais instruída tem maior acesso à justiça e mesmo com a ascensão de políticas públicas de assistência judiciária gratuita, a classe mais vulnerável desconhece dos seus direitos e permanecem na fila em busca de tratamento de saúde por mais tempo. (CARDOSO, 2017, p.53)

Consoante Henrique Ribeiro Cardoso, a judicialização da saúde possui um "ponto cego" e o judiciário precisa rever o seu papel diante das crises e omissões estatais.

Não é rara a utilização da via judicial para subverter a ordem de concessão de benefícios - furar a fila -, em uma tentativa da parte de transformar o juiz no servidor responsável pela ordenação e distribuição dos mais diversos bens e serviços públicos - saúde, educação, moradia, dentre outros. Por vezes, sem qualquer provocação ou negativa da Administração, há o ingresso de ações para assegurar direitos prestacionais, com o nítido intuito de burlar os requisitos postos em normas da Administração que selecionam e ordenam (requisitos e posição em lista, p. ex.) os beneficiários. O deferimento de requerimentos individuais mereceriam uma cautelosa análise pelo Judiciário, 
devendo-se conferir à Administração a oportunidade de demonstrar a progressividade na implantação da prestação requerida - seu planejamento, sua execução, e a situação peculiar do requerente ao ser inserido no respectivo programa ou serviço. (CARDOSO, 2017, p.54).

Sob essa perspectiva, a questão envolve um debate muito complexo, pois, há como obstaculizar a judicialização? Faz-se necessário impor limites no acesso a justiça? Esses e outros questionamentos provocam os pesquisadores que promovem a defesa dos direitos fundamentais e humanos. De certo, não se promove um direito, obstaculizando o seu acesso, precisamente, a saída não é limitar o acesso à justiça!

Em 2016, o Conselho Nacional de Justiça, através de um convênio com o Ministério da Saúde, estruturou o Núcleo de Avaliação de Tecnologia em Saúde (NAT) e o Núcleo de Apoio Técnico ao Poder Judiciário (NAT-JUS), com vista a fornecer o apoio necessário na analise das demandas que envolvem ações de saúde, com maior presteza e tecnicidade, todavia, apesar dos esforços, os núcleos de apoio não diminuíram a judicialização das demandas de saúde, apenas promoveu um ajuda técnica para os juízes e Tribunais decidirem com mais habilidade e respaldo técnico. (CARDOSO, 2017, p. 86).

Certamente, é necessária uma atuação cautelosa do judiciário em caso complexos, se utilizando do reforço ofertado pelos Núcleos de Apoio à Saúde, para o deferimento justo a dos pleitos no âmbito da saúde. Noutro giro, em tempos de crise e tantas omissões estatais, o poder judiciário tem sido uma via para a concretização do direito à saúde, não podendo se negar o importante papel no âmbito da concretização de políticas públicas. Nesse sentido, é salutar entender que as críticas a judicialização da saúde não o torna um ação ilegal, já que poder judiciário tem legitimidade para atuar decidindo questões relacionada a saúde.

Devido à insuficiente concretização de políticas públicas voltadas à área da saúde pelos entes federados, o Poder Judiciário tem sido chamado a intervir com frequência em favor de sua garantia mediante o controle de constitucionalidade (Ação Direta de Inconstitucionalidade, Ação Declaratória de Constitucionalidade18 e Arguição de Descumprimento de Preceito Fundamental). Isso porque, em que pese o art. 196 da Constituição determinar a concretização do direito à saúde por meio de "políticas sociais e econômicas que visem à redução do risco de doença e de outros agravos e ao acesso universal e igualitário às ações e serviços para sua promoção, proteção e recuperação", o Supremo Tribunal Federal (e também outros tribunais), por meio de controle difuso de constitucionalidade, tem interpretado que se trata de um direito individual, que pode ser usufruído diretamente por cada indivíduo, e não necessariamente pela implementação de uma política pública. (GONÇALVES, SILVA, 2018, p. 248) 
Notadamente, só há judicialização se houver omissão! O estado caótico na seara da saúde é perceptível desde a ausência um fornecimento de uma simples luva ${ }^{\dagger}$ para uso dos profissionais e até a falta de leitos de Unidade de Terapia Intensiva, ou seja, não estamos tratando neste artigo de omissões em casos complexos ou de ausência de medicamentos de alto custo. Logo, sob esse prisma, a judicialização é legal e aceitável, considerando a obrigação estatal de fornecer o mínimo para a sociedade brasileira, conforme preleciona o art. 197 da constituição federal.

No Brasil, falta o básico, e, talvez, a solução para a crise seja a mais óbvia possível, fornecer o básico. Destarte, é necessário que todas as ações previstas na Lei $n^{\circ}$ 8.080/90, a famigerada lei do Sistema Único de Saúde (SUS), sejam concretizadas, para que o judiciário não intervenha nessas situações simples e que não haja gastos com a máquina do judiciário, ao invés de se possibilitar a promoção de políticas públicas na seara da saúde. No entanto, talvez esse seja maior desafio, promover o acesso básico à saúde.

No que tange a judicialização de medicamentos e tratamentos de alto custo, os limites de poder judiciário precisam ser definidos, a ponto de que não haja excessos ou uma injustiça coletiva.

O novo Código de Processo Civil promoveu inúmeras alterações no sistema processualista brasileiro, a ascensão do sistema de precedentes promoveu um debate necessário no julgamento de demandas individuais e ordinárias, no âmbito da saúde, o sistema de precedentes pode ser um caminho para os limites na atuação do judiciário, os incidentes de resolução de demandas repetitivas e de assunção de competência podem contribuir para formação de precedentes e soluções proporcionais e razoáveis. (CARDOSO, 2017, p. 89).

Sem embargo, o caminho para uma uniformização de teses no Brasil ainda está em fase de crescimento, sendo necessário um convencimento maior por parte do poder judiciário na observância dos limites nos julgamentos de questões sociais como o acesso à saúde.

\section{CONSIDERAÇÕES FINAIS}

\footnotetext{
$\dagger$ "Hospital adia cirurgias por falta de luva e fio de sutura em Rio Branco" dos os pacientes que aguardavam por cirurgia na última quarta-feira (13) no Hospital das Clínicas foram mandados de volta para casa. Disponível em: <https://g1.globo.com/ac/acre/noticia/hospital-adia-cirurgias-por-falta-de-luva-e-fio-de-sutura-em-rio-branco.ghtml>. Acesso em 11 de fev.2019.
} 
Em tese, a judicialização da saúde é uma realidade no estado Brasileiro. Hodiernamente, diante da realidade, não podemos pensar em medidas radicais para limitar o acesso ao judiciário, que desaguaria numa afronta ao princípio do acesso à justiça.

O caos é visível, vivemos em uma situação fora das condições ideais, logo, a judicialização não pode ser vista com um movimento ilegal e prescindível. Todavia, o poder judiciário não é ilimitado e irrestrito, o que deve ser pensando é como enfrentar a realidade da centralidade do poder supracitado e quais os limites a serem observados no deferimento das ações individuais e coletivas referente ao direito sanitário. Os parâmetros utilizados em casos excepcionais, como o deferimento de medicamentos ou tratamentos de alto custo, devem ser construídos através de parâmetros legais, precedentes judiciais e ponderação principiológica, com vistas a proteger a universalidade da prestação dos serviços e a igualdade substancial.

No entanto, nos casos de judicialização de pleito de tratamentos básicos de saúde, em que o estado tem por obrigação legal em fornecê-los, não há motivos para repreender o poder judiciário, haja vista que não há qualquer ilegalidade na ação que visa promover o direito fundamental à saúde.

Em verdade, teoricamente, atuar em defesa da judicialização parece incoerente, haja vista as divisões de competências dos poderes definidas pela Constituição Federal, entretanto, é perceptível que o Estado brasileiro não pode respirar teorias ufanistas, que criticam veementemente as ações do poder judiciário, mas não propõem uma saída viável diante do caos da saúde. Não há como fugir da judicialização sem pensar na promoção de políticas públicas. Provavelmente, o maior desafio na retenção da judicialização seja o fornecimento de tratamentos e ações básicas no âmbito da saúde, uma vez que, com a melhoria das ações mínimas, o judiciário só enfrentaria questões complexas que seriam cuidadosamente estudadas e solucionadas. Sabe-se que a realidade não é essa, o poder judiciário enfrenta desde questões básicas, como um pleito de realização de cirurgia simples indo até um pedido de fornecimento de medicamentos de alto custo.

A judicialização da saúde merece críticas, considerando que o excesso de justiça não é benéfico em nenhuma área prestacional, conduto, maior crítica merece os Entes federados que detém competência solidária na prestação de políticas pública no âmbito da saúde e tratam o fornecimento universal da saúde como uma questão fadada ao insucesso. 


\section{REFERÊNCIAS}

BARROSO, Luís Roberto. Judicialização, Ativismo Judicial e Legitimidade

Democrática. Rio de Janeiro, 2012 Disponível em: < https://www.e-

publicacoes.uerj.br/index.php/synthesis/article/view/7433>. Acesso em 09 nov. 2018.

BRASIL. Constituição. Constituição da República Federativa do Brasil. Brasília: Senado Federal, 1988. Disponível em: <http://www.planalto.gov.br〉. Acesso em: 15 out. 2018.

CARBONELL, Miguel. Neoconstitucionalismo(s). 4. ed. Madri: Trotta, 2009.

CARDOSO, Henrique Ribeiro. O Parodoxo da Judicialização das Políticas Públicas de Saúde no Brasil: Um ponto cego do direito?. 1. Ed.. Rio de Janeiro: Lumen Juris, 2017.

CONFERÊNCIA NACIONAL DE SAÚDE. Relatório final. Brasília, 1986. Disponível em<http://bvsms.saude.gov.br/bvs/publicacoes/8_conferencia_nacional_saude_relatorio_final .pdf $>$. Acesso em 29 out. 2018.

DECLARAÇÃO UNIVERSAL DOS DIREITOS HUMANOS. Disponível em <http://www.ohchr.org/EN/UDHR/Documents/UDHR_Translations/por.pdf.>Acesso em: 15 set. 2018.

FIGUEIREDO, Eduardo, GIBRAN, Sandro Mansur. O Ativismo Judicial, O Princípio da Separação dos Poderes e a Ideia de Democracia. 2016. Disponível em:

<http://revista.unicuritiba.edu.br/index.php/percurso/article/viewFile/1728/1122> . Acesso em 01 nov. 2018.

GONÇALVES, Everton das Neves; SILVA, Marco Aurélio Souza da. A judicialização do direito à saúde no constitucionalismo brasileiro: escassez, custos e eficiência econômicosocial. Revista Eletrônica do Curso de Direito da UFSM, Santa Maria. Disponível em: < https://periodicos.ufsm.br/revistadireito/article/view/29084 >. Acesso em: 09 nov. 2018.

LOCKE, John. O Segundo Tratado sobre o Governo Civil. Tradução: Magda Lopes e Marisa Lobo da Costa. Editora Vozes: Petrópolis, 1994.

MANCUSO, Rodolfo de Camargo. Acesso à justiça: condicionantes legítimas e ilegítimas. São Paulo: Editora Revista dos Tribunais, 2011. 
MARTINS, Flavia Bahia. O Direito Fundamental à Saúde no Brasil sob a Perspectiva do Pensamento Constitucional Contemporâneo. Dissertação de Mestrado. Rio de Janeiro: PUC, Departamento de Direito, 2008. Disponível em:

<http://www.dominiopublico.gov.br/download/teste/arqs/cp077034.pdf>. Acesso em 09 nov. 2018.

MONTESQUIEU, Barão de. Do Espírito das Leis. São Paulo: Martin Claret, 2007

NOVELINO, Marcelo. Curso de direito constitucional. 10. ed. Salvador: Juspodvim: 2015.

POZZOLO, Susanna. Neoconstitucionalismo: um modelo constitucional ou uma concepção da constituição? 2005. Disponível em:

<http://www.esdc.com.br/seer/index.php/rbdc/article/view/322>. Acesso em: 17 out. 2018

SARLET, Ingo Wolfgang. Algumas considerações em torno do conteúdo, eficácia e efetividade do direito à saúde na constituição de 1988. Revista Diálogo Jurídico, Salvador: 2002. Disponível em: < http://www.direitopublico.com.br >. Acesso em: 11 set.2018.

SARLET, Ingo Wolfgang; FIGUEIREDO, Mariana Filchtiner. Reserva do possível, mínimo existencial e direito à saúde: algumas aproximações. Revista Doutrina TRF4, Salvador: 2007. Disponível em: <http://www.revistadoutrina.trf4.jus.br/index.htm?http://www.revistadoutrina.trf4.jus.br/a rtigos/edicao024/ingo_mariana.html>. Acesso em: 28 out. 2018.

SILVA, José Afonso da. Comentário contextual à constituição. $1^{\mathrm{a}}$. ed. São Paulo: Malheiros, 2006. 